\title{
BMJ Global Health Use of social media platforms by manufacturers to market breast-milk substitutes in South Africa
}

\author{
Catherine Pereira-Kotze (D , ${ }^{1}$ Tanya Doherty (D) , , ${ }^{1,2}$ Elizabeth C Swart (D) ${ }^{3,4}$
}

To cite: Pereira-Kotze C, Doherty T, Swart EC. Use of social media platforms by manufacturers to market breast-milk substitutes in South Africa. BMJ Global Health 2020;5:e003574. doi:10.1136/ bmjgh-2020-003574

Handling editor Eduardo Gómez

Received 29 July 2020 Revised 3 November 2020 Accepted 11 November 2020

Check for updates

(c) Author(s) (or their employer(s)) 2020. Re-use permitted under CC BY-NC. No commercial re-use. See rights and permissions. Published by BMJ.

${ }^{1}$ School of Public Health, University of the Western Cape Faculty of Community and Health Sciences, Cape Town, South Africa

${ }^{2}$ Health Systems Research Unit, South African Medical Research Council, Tygerberg, South Africa ${ }^{3}$ Dietetics \& Nutrition, University of the Western Cape Faculty of Community and Health Sciences, Cape Town, South Africa

${ }^{4}$ DSI/NRF CoE in Food Security, University of the Western Cape, Bellville, South Africa

\section{Correspondence to} Catherine Pereira-Kotze; catherinejanepereira@gmail. com

\section{ABSTRACT}

In South Africa (SA), exclusive breast feeding remains rare, with breast-milk substitutes (BMS) commonly being used in ways that are detrimental to infant and young child nutrition, health and survival. The use of internet, digital and mobile platforms has increased, including in low-income and middle-income countries, like SA and these platforms are avenues for BMS marketing. SA has national legislation (Regulation R991) to enforce the International Code of Marketing of BMS. This paper aims to provide pertinent examples of how BMS manufacturers in SA use social media to market their products thus violating national regulations. A digital (and social media) ethnography approach was used to study BMS organisations' activity on Facebook and Instagram. Purposively selected examples of social media posts observed (from 2015 to 2019) were included, and content analysed in terms of national legislation. Several examples of BMS social media marketing are presented and interpreted according to provisions of national regulations that they violate. BMS manufacturers have found ways on social media to market their products in a media space that is complex to regulate, and where it is difficult to enforce national regulations. It is necessary to engage with stakeholders, notably social media companies, to alert them to relevant regulations applicable to their platforms. Monitoring the marketing of products for infants and young children by national governments needs to include online and digital platforms especially social media.

\section{INTRODUCTION}

There is global guidance and national legislation describing restrictions on the marketing of foodstuffs for infants and young children. ${ }^{1-3}$ Breast-milk substitutes (BMS) (also known as infant formula) are one of the categories of products covered by such guidance and legislation. In South Africa (SA), the Regulations R991 relating to foodstuffs for infants and young children (hereafter referred to as 'Regulation R991') was finalised in 2012, and this serves to legislate the International Code of Marketing of BMS (hereafter referred to as 'the international Code'). ${ }^{12}$ A provision in the SA legislation is that employees of BMS manufacturers cannot contact members of the
Summary box

WHO provides guidance in the International Code of Marketing of Breast-milk Substitutes (BMS) from which countries can develop national legislation.

- The use of internet, digital and mobile platforms has increased, including in low-income and middleincome countries, and these platforms are avenues for BMS marketing.

- BMS manufacturers have found ways on social media to market their products in a media space that is complex to regulate, and where it is difficult to enforce national regulations.

- Monitoring of marketing of products for infants and young children by national governments needs to include online and digital platforms especially social media.

public to market their products, including via 'internet sites', ${ }^{2}$ which includes social media platforms. In general, the capacity to monitor and enforce regulations are stretched, which compounds the entrenched difficulties in regulating social media platforms. Promulgation of Regulation R991 in 2012 was followed by the publication of stricter global guidance on the marketing of foodstuffs for infants and young children. ${ }^{3}$ The concurrent growth in internet, digital and mobile platforms, including in low-income and middle-income countries like $\mathrm{SA}^{45}$ has seen innovative digital techniques being used by companies to market their products. ${ }^{6}$

SA has high rates of poverty and inequality. ${ }^{7}$ The National Department of Health (NDoH), in line with WHO, recommends that infants are exclusively breastfed until 6 months, with the introduction of safe, adequate and appropriate complementary foods at 6 months and continued breastfeeding until 2 years and beyond. ${ }^{8}{ }^{9}$ However, in SA, exclusive breast feeding remains extremely rare $^{10}$ with BMS commonly being used in ways that are detrimental to infant and young child nutrition (IYCN), health, and survival. ${ }^{11}$ Increased 
marketing of any product influences consumer buying decisions. ${ }^{12}$ Marketing of BMS-including on social media platforms-could potentially increase social acceptance, desirability and use, to the detriment of infants.

There is no published research in SA to show whether BMS manufacturers use social media to market their products. There is also a lack of evidence to show whether their marketing practices violate national law (other than anecdotal reports). To fill the current void in literature, this paper aims to provide pertinent examples of how BMS manufacturers in SA use social media to market their products and how this marketing relates to existing national regulations. The purpose of this is to create awareness of these practices and to provide recommendations on how Regulation R991 should be interpreted within the context of social media.

A digital (and more specifically, social media) ethnography approach was used. ${ }^{13}$ This involved studying participant's (in this case, organisations') activity and behaviour on social media platforms. The first author observed sponsored posts by BMS manufacturers on their own personal Facebook newsfeed and then actively sought out different Facebook pages and Instagram handles managed by manufacturers of BMS in SA. Facebook was selected because it is the most popular public social media application used globally (and one of the top social media apps used in $\mathrm{SA}^{14}$ ), and Instagram is the quickest growing social media platform in SA. ${ }^{15}$ WhatsApp was not included because the content is not publicly available for scrutiny.

The first author had already 'liked' or 'followed' pages and handles related to IYCF, in a personal and professional capacity. None of the pages or handles 'liked' by the first author were set up or managed by an industry or industry-affiliated organisation. However, the first author was exposed to specific sponsored (paid for) posts from industry and industry-affiliated organisations that appeared on the first author's newsfeed, unsolicited, due to the advertising algorithms used by social media platforms. Examples of social media posts that the first author has observed on their newsfeed of Instagram or Facebook (from 2015 to 2019) have been included in this paper as they most commonly appeared as sponsored posts, but also provide clear examples of violations to the national R991 regulations. We include examples from two manufacturers as these companies had the largest social media presence. The posts selected were then interpreted according to the provisions of the regulations that they violate and an image and/or weblink is provided to illustrate the violation. Since publicly available information obtained online was used and no participants were included in the research, ethical clearance was not required.

\section{ARE BMS MANUFACTURERS VIOLATING NATIONAL LEGISLATION USING SOCIAL MEDIA MARKETING?}

There are clear and numerous examples of violations of provisions of the Regulation R991, by different manufacturers, using social media platforms to market products for infants and young children.

The first observation on social media is that one BMS manufacturer has several different pages and groups related to infant and young child feeding (IYCF), targeted to consumers, globally and for specific countries, such as SA (table 1). Some Facebook groups are categorised as 'baby goods'; while there is no standard definition for the age range of what a 'baby' could refer to, a reasonable assumption would be that this includes infants and young children. The SA Regulation R991 applies to foodstuffs for infants and young children under the age of 36 months. ${ }^{2}$

An example of a violation of SA's Regulation R991 (as well as an international Code violation) is provided from a BMS manufacturer's Facebook page. On 20 and 21 June 2019, the following was posted on the 'Nestlé Baby

Table 1 An example of various Facebook pages that SA consumers have access to and that are managed by a single BMS manufacturer (accessed (online) 9 July 2020)

\begin{tabular}{|c|c|c|c|}
\hline $\begin{array}{l}\text { Name of facebook } \\
\text { page }\end{array}$ & $\begin{array}{l}\text { Description of } \\
\text { page }\end{array}$ & $\begin{array}{l}\text { No of likes } \\
\text { (2 November 2020) }\end{array}$ & Weblink to the page or group \\
\hline Nestlé (global) & Product/Service & 11502640 & https://www.facebook.com/Nestle \\
\hline Nido SA & Product/Service & 62101 & https://www.facebook.com/Nido-South-Africa-1503515943233615/ \\
\hline $\begin{array}{l}\text { Nestlé Breakfast } \\
\text { Cereals SA }\end{array}$ & $\begin{array}{l}\text { Food \& drink } \\
\text { company }\end{array}$ & 49841 & https://www.facebook.com/MiloCerealZA/ \\
\hline $\begin{array}{l}\text { Nestlé Nutrition } \\
\text { Institute }\end{array}$ & Science & 17871 & https://www.facebook.com/NestleNutritionlnstitute/ \\
\hline Nespray SA & $\begin{array}{l}\text { Baby Goods/Kids } \\
\text { Goods }\end{array}$ & 8270 & https://www.facebook.com/NesprayZA/ \\
\hline Nestlé NANKID 4 SA & Product/Service & 4316 & https://www.facebook.com/Nankid4SA \\
\hline
\end{tabular}

*Formerly called Nestlé Start Strong Stay Strong.

BMS, breast-milk substitutes; SA, South Africa. 
\&

Nestlé Baby \& Me South Africa •

20 June $2019 \cdot 8$

Hey, mom! For all that you do, we'd like to thank you. Join us for a conversation on WhatsApp, and stand a chance to win rewards for you and your child.

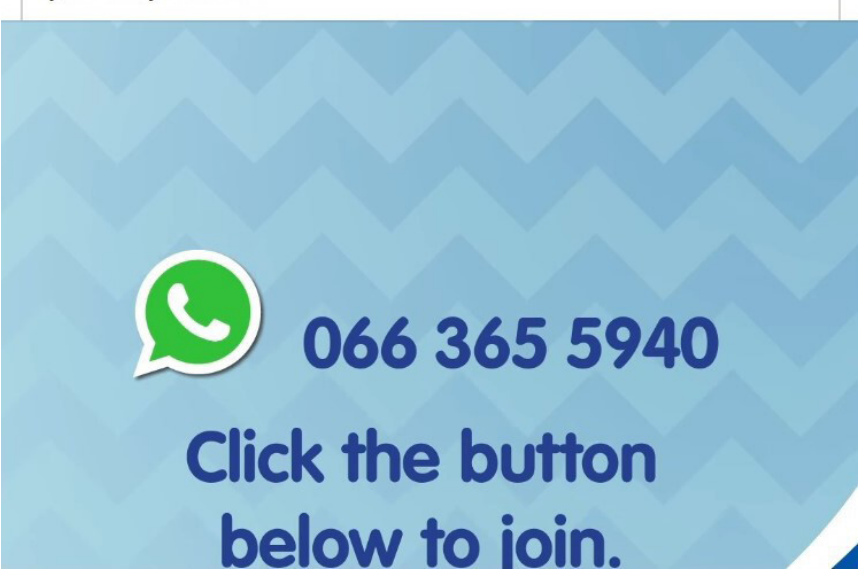

Figure 1 Example of a Facebook post from 'Nestlé baby \& Me South Africa' page that violates provision 7 (1) and 7 (2) of the SA regulation R991. ${ }^{29} \mathrm{SA}$, South Africa.

\& Me' South Africa page, stating: Hey, mom! For all that you do, we'd like to thank you. Join us for a conversation on WhatsApp, and stand a chance to win rewards for you and your child' alongside a video that includes the Nestlé LactoKid 4 product ('a delicious creamy drink for growing children' and indicated from 3 to 5 years) and a WhatsApp phone number. Therefore, the Nestlé company is inviting mothers to join a conversation on WhatsApp and to win rewards for the mother and child (figure 1). While the product is not a 'designated product' according to the Regulation R991 (because designated products are those targeted to children under the age of 36 months), it still contravenes one of the regulations related to promotional practice.

Provision 7 (1) of the Regulation R991 states that 'No person shall undertake or participate in any promotional practice in respect of (BMS); 7 (2) Promotional practices or devices in respect of the products listed in sub-regulation 7 (1) include, but are not limited to: ... Direct/indirect contact between company personnel and members of the public in furtherance of or for the purpose of promoting the [BMS-related] business of the company... ; Indirect contact includes internet sites hosted on behalf of an SA entity, television and radio, telephone or internet help lines, mother and baby clubs but excludes contact w.r.t. product quality complaints....? By inviting mothers to join a conversation on an instant messaging platform (WhatsApp), a BMS manufacturer (Nestlé) is clearly inviting direct/indirect contact between their company's personnel and members of the public (in this case, it clearly states 'moms'). According to Provisions 7 (1) and 7 (2), this should not be allowed to take place. The example described is, therefore, a direct violation of the SA Regulation R991. This type of practice takes place regularly by this BMS manufacturer

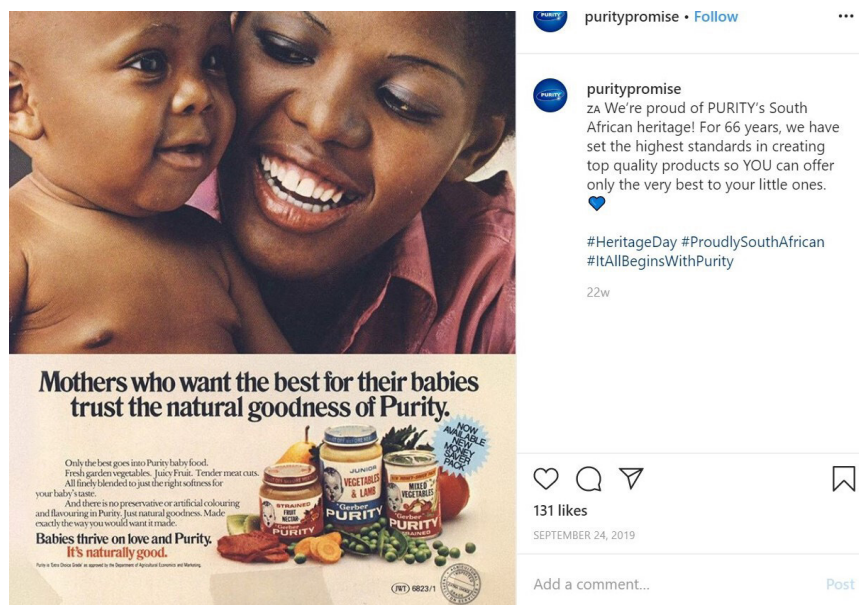

Figure 2 Example of an Instagram post from purity that violates provisions 2 (1) and 3 of the SA regulation R991. ${ }^{30}$ SA, South Africa.

on Facebook. Sometimes posts like this could appear on the newsfeed of any person interested in IYCF, even if that person did not like the page responsible, by means of sponsored posts that appear when people have shown an interest in similar content. This type of indiscriminate marketing can be harmful to the public, by building up brand recognition or loyalty in consumers that could lead to inappropriate or unnecessary purchasing of products.

The second example comes from Instagram, where on 24 September 2019, the following was posted: puritypromise: We're proud of PURITY's South African heritage! For 66 years, we have set the highest standards in creating top quality products so YOU can offer only the very best to your little ones. \#HeritageDay \#ProudlySouthAfrican \#ItAllBeginsWithPurity' alongside the figure 2 which includes previous labels of Purity products that were used, that have an image of an infant that could be younger than 6 months on the label of the product.

From Regulation R991, in the 'Labelling, Composition, Packaging and Manufacturing Matters' section, Provision 3 states that The company logo, brand name and logos indicating endorsement by specific certifying organisations shall be permitted, provided they do not contain a picture of an infant, young child or other humanised figure. ${ }^{2}$ The above advert displays old products from Purity with labels that violate this provision. Furthermore, the statement that 'Babies thrive on love and Purity' can be misinterpreted. While there is no standard definition for what a baby means, this could be interpreted by mothers to mean that infants under the age of 6 months can consume Purity, which is a violation of Provision 2 (1) (a) which states that '2 (1) No person shall import, offer for sale or sell any-(a) foodstuff other than infant formula or infant formula for special dietary managements of specific medical conditions which are represented as suitable for infants younger than 6 months of age. ${ }^{2}$ Due to the image of an undetermined aged child on the labels of the products and the use of the word baby, a mother or caregiver may interpret this product 


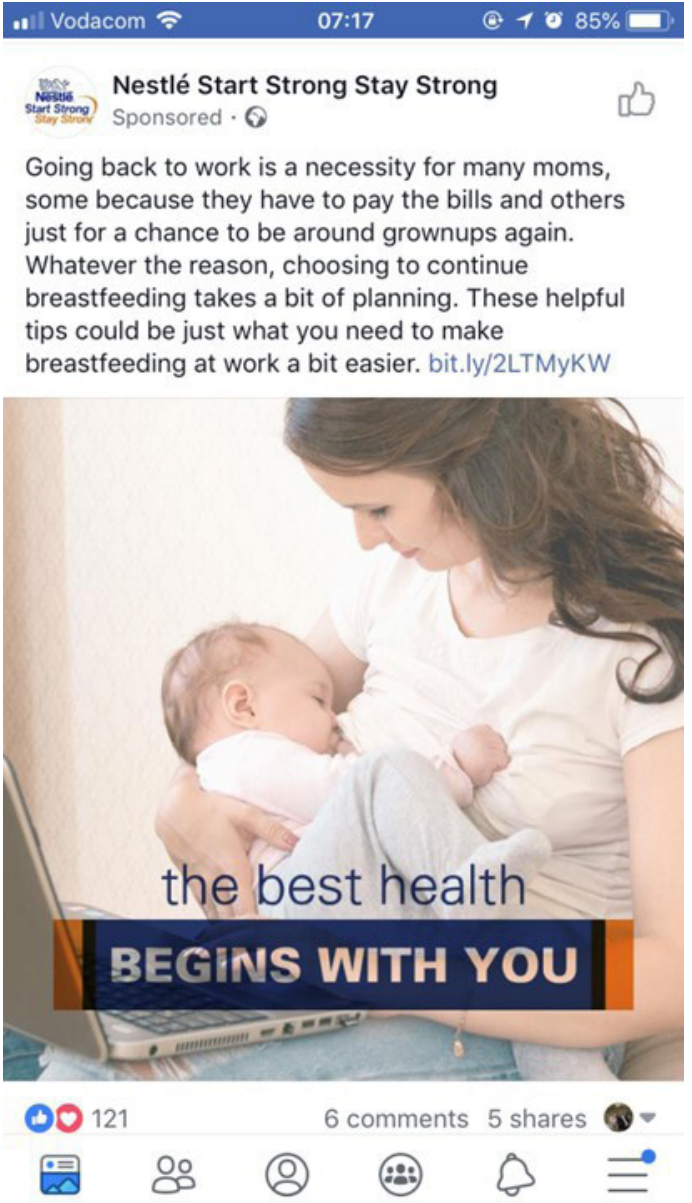

Figure 3 Example of a Facebook post by a Nestlé Facebook page that violates provision 7 (5) of the regulation R991.

to be appropriate for infants under the age of 6 months, which contravenes this provision.

During World Breastfeeding Week 2018 (on 6 August 2018), the 'Nestlé Start Strong Stay Strong' Facebook page (which has been subsequently renamed to 'Nestlé Baby and Me South Africa') shared a post including the following statement: 'Going back to work is a necessity for many moms, some because they have to pay the bills and others just for a chance to be around grownups again. Whatever, the reason, choosing to continue breastfeeding takes a bit of planning. These helpful tips could be just what you need to make breastfeeding at work a bit easier. bit.ly/2LTMyKW' (see figure 3). The shortened link goes to a website which contains information on 'Returning to Work From Maternity Leave' published on 31 December $2015,{ }^{16}$ and this weblink is still available. The post displayed in figure 3 was subsequently deleted from the 'Nestlé Stay Strong Start Strong' Facebook page and therefore there is not a direct weblink to the original post, however, what is shown in figure 3 is a screengrab of a sponsored post that was on Facebook at the time.

The above example (figure 3) is a direct violation of Regulation R991, as no companies can provide information to the public on IYCN. This is covered in Provision 7 (5) which states the following: 7 (5) No manufacturer,

.11 Vodacom \& 20:55 ब1\% $49 \%$ 믈

(3) Nestlé

vesty Sponsored $\cdot 6$

We understand how hard it can be to get your kids to eat their spinach, peas or carrots. That's why we're hosting a Nestlé Secret Moms' Club, where we share ideas on how you can give your kids all they need to be healthy, active and happy.

\#NestleSecretMomsClub

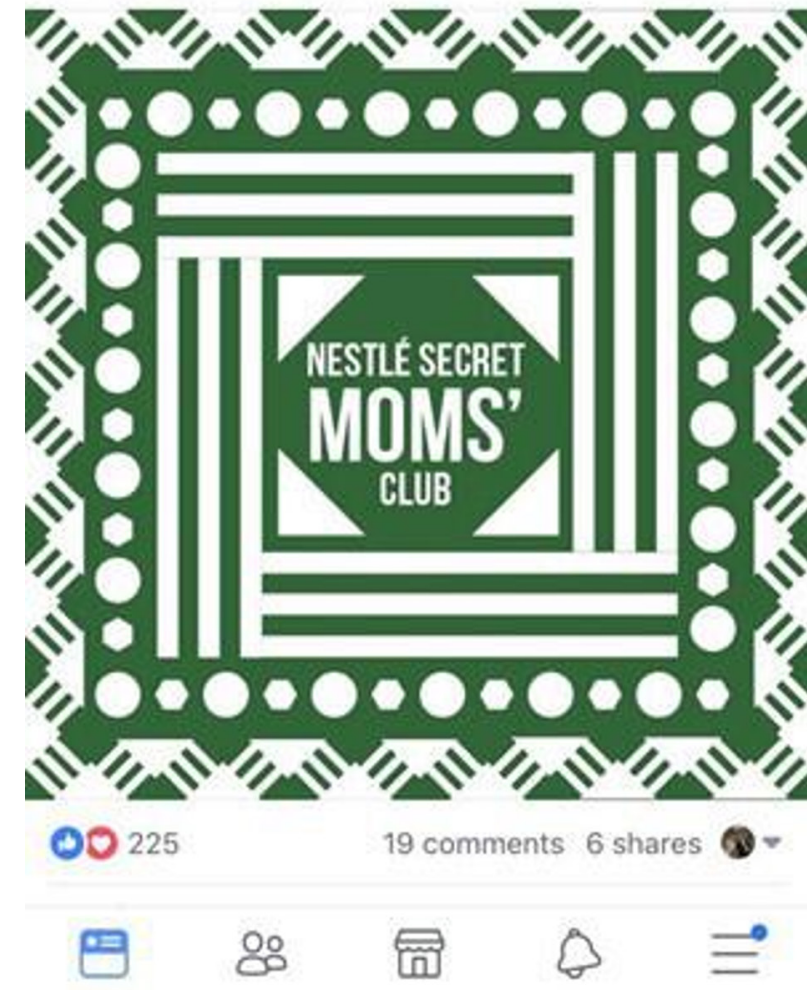

Figure 4 Example of a Facebook post by a Nestlé Facebook page that violates provision 7 (5) of the regulation R991. $^{31}$

distributor, retailer, importer or person on behalf of the aforementioned shall produce, distribute or present educational information on IYCN. ${ }^{2}$ Therefore, it is a violation for a BMS manufacturer, or anyone on their behalf (in the example in figure 3, this is a BMS manufacturer's Facebook page) to share information on IYCN, which is exactly what this post is doing.

In the middle of July 2018 (2 weeks before World Breastfeeding Week), the Nestlé (global) page, accessible to South Africans, shared the following post: 'We understand how hard it can be to get your kids to eat their spinach, peas or carrots. That's why we're hosting a Nestlé Secret Moms' Club, where we share ideas on how you can give your kids all they need to be healthy, active and happy. \#NestleSecretMomsClub' (figure 4)

Once again, this is a violation of Provision 7 (5) described above, because it is an invitation for mothers to join a group where they will receive information on IYCN. It is concerning that the BMS manufacturer portrays 
this as a 'secret' club implying that mothers should not inform anyone about this space and what is shared there.

A last example, which is also a clear violation of Provision 7 (5), is a post from 19 August 2017 by the 'Nestlé Start Strong Stay Strong' Facebook page (this was its name at the time) that stated: 'At Nestlé Start Strong Stay Strong, we firmly encourage and believe in Breastfeeding! VIEW this global video [from another Nestlé marketing page] and watch the benefits of breastfeeding.' The link displays a video, shared by a BMS manufacturer, describing 10 benefits of breast feeding. ${ }^{17}$

The examples provided show that various manufacturers use strategies to directly and indirectly market products for infants and young children on platforms like social media that are difficult to monitor. Manufacturers continue to find innovative, alternative ways to market their products to consumers, particularly mothers of infants and young children, using complex advertising algorithms, some of which have been specifically developed for social media. ${ }^{6}$

\section{WHY SHOULD WE BE CONCERNED ABOUT BMS MANUFACTURERS USING SOCIAL MEDIA MARKETING?}

The examples presented here display that, in SA, BMS manufacturers use social media in ways which could negatively influence optimal IYCF practices, by violating provisions of national regulations. This is especially concerning, because BMS manufacturers often publicly claim to comply with national regulations and subscribe to voluntary Codes of Conduct. For example, Nestlé has been included in the Financial Times Stock Exchange Group (FTSE) 4 Good Index Series since 2011, which monitors companies' environmental, social and governance practices. ${ }^{18}$ Nestlé asserts that they were the first BMS manufacturer to be included in the FTSE 4 Good Index series. ${ }^{19}$ Since 2017, Danone (an international BMS manufacturer) has also been included on this index. ${ }^{20}$ It can be assumed that investors and the public are led to believe that indexed companies such as Nestlé comply with international guidance and national regulations. However, from the examples provided above, all of which are still available online for consumers to access (except for figure 3), this is not the case. Further, we are of the opinion that social media marketing, which often purports to have an education purpose, forms part of 'amplification' within the broad category of 'information management' in the categorisation of corporate political activity proposed by Mialon et al. ${ }^{21}$

Manufacturers have a legal obligation to comply with national legislation and international guidance. Yet, BMS manufacturers continue to be creative in identifying 'loopholes' that are not being actively monitored whereby they can directly violate these laws, with minimal, if any, consequences. BMS manufacturers need to take genuine responsibility and ownership regarding abiding to international guidance and national legislation. It is publicly known that companies have large marketing budgets. ${ }^{22}$
The largest food and beverage manufacturer (which also manufactures BMS), Nestlé, has information publicly available in an annual Financial Statements report. ${ }^{23}$ This document shows that 'Marketing and administration expenses' for the whole company are reported together and for 2018, this totalled 20003 million CHF (Swiss Francs), currently the equivalent of \pm US $\$ 20562880000$ (around US\$20 billion). However, these reports do now show the breakdown of marketing compared with administration expenses, neither the product/product category specific breakdown.

Over recent years, organisations such as WHO have documented the complex algorithms and networks used by companies, including BMS manufacturers, to tailor their online and digital marketing. ${ }^{6}$ Social media marketing, in particular, is insidious and it is difficult to keep up with the pace at which marketing strategies develop and what tactics are used by various social media platforms-for example, Facebook and Instagram as presented here-but also other social media platforms, websites and online content. These messages and advertisements could be reaching both current and future parents and caregivers, as well as children, who are increasingly accessing social media. This practice therefore has the potential to have intergenerational negative impacts. The WHOUNICEF-Lancet Commission of February 2020 entitled 'A future for the world's children?' provides strong recommendations for improved regulation (including the adoption of a new protocol to the United Nations Convention on the Rights of the Child) regarding products marketed to children with the potential to cause harm; the categories of products listed include BMS. $^{24}$

\section{WHAT CAN BE DONE TO DECREASE THE VIOLATIONS OF NATIONAL LEGISLATION THAT TAKE PLACE ON SOCIAL MEDIA?}

There are a variety of stakeholders that need to be involved in ensuring that BMS manufacturers do not violate national legislation. Monitoring marketing of BMS through social media is particularly challenging because social media and the internet crosses geographical boundaries; however, social media platforms should be informed of the international Code and globally applicable guidelines. Within a specific country, the BMS manufacturer should bear the penalty of transgressions (if penalties have been specified in national regulations), with social media platforms having a secondary accountability, thus disallowing posts that are in violation with international guidance or national regulations. Income generation by social media platforms should not be at the cost of the health of infants and young children. In $\mathrm{SA}$, the NDoH needs to increase awareness of the interpretation of Regulation R991. A Question and Answer Guide for Health Professionals and Industry ${ }^{25}$ that was published 6 years ago has not been updated despite changes to international guidance. Updating regulations is an extremely lengthy process, therefore, an alternative 
could be to include a provision in the regulation that will allow an automatic update should international guidelines become stronger than national legislation. Government and the NDoH also need to allocate more resources to monitoring and enforcement of the regulations and consider establishing a centralised body for this purpose-either in the NDoH, Directorate: Nutrition or Directorate: Food Control. Currently, penalties are described in the Foodstuffs, Cosmetics and Disinfectants $\mathrm{Act}^{26}$ — which is where Regulation R991 is located-and include provisions of fines or imprisonment. Regulation R991 was developed at the national level; however, the monitoring of regulations is the responsibility of environmental health officers who work at a municipal level. This creates a gap in effective monitoring and evaluation of the regulations.

The COVID-19 pandemic appears to have provided BMS manufacturers with new opportunities to violate the international Code and national legislation in some countries, in the form of providing donations, a form of constituency recruitment under coalition management as per Mialon's classification of corporate political activity, ${ }^{21}$ or using other ways to market products. ${ }^{27}$ In the current time of a global pandemic, the capacity for monitoring of the international Code, as well as other basic health services related to child health and nutrition (eg, growth monitoring and promotion, health promotion and nutrition education, etc) may be weakened in many countries. With the economic impacts of COVID-19 and predicted catastrophic hunger pandemic to follow, ${ }^{28}$ now, it is of utmost importance to protect, promote and support breastfeeding as a key component of optimal IYCF.

\section{CONCLUSION}

Manufacturers of BMS and foods for infants and young children claim to comply with national and international guidance. However, these same manufacturers are using calculated marketing techniques to engage directly with consumers using social media. It is, therefore, necessary to engage with various stakeholders, notably social media companies, to alert them to relevant regulations applicable to their platforms. Monitoring of marketing of products for infants and young children by national governments needs to include online and digital platforms especially on social media.

Contributors $\mathrm{CP}-\mathrm{K}, \mathrm{TD}$ and ECS all conceptualised and planned the content of the manuscript. CP-K wrote the first draft, including the identification of the examples to be used; TD and ECS provided comprehensive reviews and additions to all sections of the manuscript.

Funding This publication received support from the DSI/NRF Center of Excellence in Food Security UID 91490. TD's time was supported by the South African Medical Research Council.

Competing interests None declared.

Patient consent for publication Not required.

Provenance and peer review Not commissioned; externally peer reviewed.

Data availability statement The authors confirm that the data supporting the findings of this study are available within the article and its Reference list. All data are available at publicly accessible weblinks, which were available at the time of publication.

Open access This is an open access article distributed in accordance with the Creative Commons Attribution Non Commercial (CC BY-NC 4.0) license, which permits others to distribute, remix, adapt, build upon this work non-commercially, and license their derivative works on different terms, provided the original work is properly cited, appropriate credit is given, any changes made indicated, and the use is non-commercial. See: http://creativecommons.org/licenses/by-nc/4.0/.

\section{ORCID iDs}

Catherine Pereira-Kotze http://orcid.org/0000-0003-3061-6511

Tanya Doherty http://orcid.org/0000-0003-1592-0080

Elizabeth C Swart http://orcid.org/0000-0002-7786-3117

\section{REFERENCES}

1 World Health Organisation (WHO). International Code of marketing of breast-milk substitutes. Geneva: WHO, 1981. Available: https:// www.who.int/nutrition/publications/code_english.pdf [Accessed 15 May 2020].

2 National Department of Health (NDoH). Regulation R991: regulations relating to foodstuffs for infants and young children. Pretoria: Government Gazette (Department of Health), 2012. https://www.gov. za/sites/default/files/gcis_document/201409/35941rg9868gon991. pdf

3 World Health Assembly (WHA). WHA resolution 69.9: maternal, infant, and young child nutrition. guidance on ending the inappropriate promotion of foods for infants and young children. Geneva: WHO, 2016. https://apps.who.int/gb/ebwha/pdf_files/ WHA69/A69_7Add1-en.pdf

4 Internet World Stats Website. Internet world Stats: usage and population statistics. Internet penetration in Africa 2020 - Q1 March, 2020. Available: www.internetworldstats.com/stats1.htm [Accessed 15 Jul 2020].

5 Statista Website. Digital population in South Africa as of January 2020 (in millions), 2020. Available: https://www.statista.com/ statistics/685134/south-africa-digital-population/ [Accessed $15 \mathrm{Jul}$ 2020].

6 World Health Organisation (WHO). Tackling food marketing to children in a digital world: trans-disciplinary perspectives. Geneva: WHO, 2016. http://www.euro.who.int/_data/assets/pdf_file/0017/ 322226/Tackling-food-marketing-children-digital-world-transdisciplinary-perspectives-en.pdf

7 Statistics South Africa (Stats SA). Men, women and children: findings of the living conditions survey 2014/15. Pretoria: Stats SA, 2018. http://www.statssa.gov.za/publications/Report-03-10-02\%20/ Report-03-10-02\%202015.pdf

8 National Department of Health (NDoH). Infant and young child feeding policy. Pretoria: National Department of Health (NDoH), 2013. https://health-e.org.za/wp-content/uploads/2013/09/IYCF Policy_2013.pdf

9 World Health Organisation (WHO) website. WHO fact sheet: infant and young child feeding, 2018. Available: https://www.who.int/newsroom/fact-sheets/detail/infant-and-young-child-feeding [Accessed 5 Jul 2019].

10 National Department of Health $(\mathrm{NDoH})$, Statistics South Africa (Stats $\mathrm{SA}$ ), South African Medical Research Council (SAMRC), and ICF. South Africa demographic and health survey 2016: key indicators. Pretoria, South Africa and Rockville, Maryland, USA: NDoH, Stats SA, SAMRC and ICF., 2017. https://www.statssa.gov.za/ publications/Report\%2003-00-09/Report\%2003-00-092016.pdf

11 National Department of Health (NDoH), Statistics South Africa (Stats SA), South African Medical Research Council (SAMRC), and ICF. South Africa demographic and health survey 2016. Pretoria, South Africa and Rockville, Maryland, USA: NDoH, Stats SA, SAMRC and ICF, 2019. https://dhsprogram.com/pubs/pdf/FR337/FR337.pdf

12 Global System for Mobile Communications Association (GSMA). Connected Society: the state of mobile Internet connectivity 2019. London: GSMA, 2019. https://www.gsma.com/ mobilefordevelopment/wp-content/uploads/2019/07/GSMA-Stateof-Mobile-Internet-Connectivity-Report-2019.pdf

13 Postill J, Pink S. Social media ethnography: the digital researcher in a messy web. Media Int Aust 2012;145:123-34.

14 Data Reportal website. Digital 2020: South Africa, 2020. Available: https://datareportal.com/reports/digital-2020-south-africa [Accessed 9 Jul 2020].

15 Ornico \& World Wide Worx. SA social media landscape 2019, 2019. Available: https://www.iabsa.net/assets/Usedebbieiabsanet/Social_ 
Media_Landscape_2019_report,_Executive_Summary.pdf [Accessed 25 Sep 2019].

16 Available: https://www.babyandme.nestle.co.za/returning-workmaternity-leave [Accessed 19 Oct 2020].

17 Available: https://www.facebook.com/watch/?v=1034581823311127 [Accessed 19 Oct 2020].

18 FTSE Russell website. FTSE4Good index series, 2020. Available: https://www.ftserussell.com/products/indices/ftse4good [Accessed 15 May 2020].

19 Nestlé website. The FTSE4Good investment index, 2020. Available: https://www.nestle.com/ask-nestle/health-nutrition/answers/what-isftse4good [Accessed 15 May 2020].

20 FTSE Russell website. FTSE4Good BMS verification, 2020. Available: https://www.ftserussell.com/ftse4good-breast-milksubstitutes-bms [Accessed 15 Jul 2020].

21 Mialon M, Crosbie E, Sacks G. Mapping of food industry strategies to influence public health policy, research and practice in South Africa. Int J Public Health 2020;65:1027-36.

22 Hastings G, Angus K, Eadie D, et al. Selling second best: how infant formula marketing works. Global Health 2020;16:77.

23 Nestlé. Financial statements 2018. consolidated financial statements of the Nestlé group 2018: 152nd financial statements of Nestlé S.A. Geneva: KPMG, 2018. https://www.nestle.com/sites/default/files/ asset-library/documents/library/documents/financial_statements/ 2018-financial-statements-en.pdf

24 Clark H, Coll-Seck AM, Banerjee A, et al. A future for the world's children? A WHO-UNICEF-Lancet Commission. Lancet 2020;395:605-58.
25 National Department of Health (NDoH). Guidelines to Industry and Health Care Personnel: The Regulations Relating to Foodstuffs for Infants \& Young Children. Pretoria: NDoH, 2014. http://www.health. gov.za/index.php/shortcodes/2015-03-29-10-42-47/2015-04-3009-10-23/2015-04-30-09-11-35/category/207-regulations-labellingand-advertising?download=742:r991-guidelines-to-industry-andhealth-care-personnel-may2014-1

26 National Department of Health (NDoH). Foodstuffs, cosmetics and disinfectants act No. 54 of 1972. government Gazette 32012, 2009. Available: https://www.gov.za/documents/foodstuffscosmetics-and-disinfectants-act-2-jun-1972-0000 [Accessed 3 Sep 2020].

27 van Tulleken C, Wright C, Brown A, et al. Marketing of breastmilk substitutes during the COVID-19 pandemic. Lancet 2020. doi:10.1016/S0140-6736(20)32119-X. [Epub ahead of print: 08 Oct 2020].

28 Global Network Against Food Crises \& Food Security Information Network (FSIN). 2020 global report on food crises: joint analysis for better decisions. Rome: World Food Programme (WFP), 2020. https://www.wfp.org/publications/2020-global-report-food-crises

29 Available: https://www.facebook.com/watch/?v=508735629665736 [Accessed 19 Oct 2020].

30 Available: https://www.instagram.com/p/B2yOjwbD5CC/ [Accessed 19 Oct 2020].

31 Available: https://www.facebook.com/NestleESAR/posts/ 1597953056994377 [Accessed 19 Oct 2020]. 